\title{
PROTAGONISMO EN EL SISTEMA DE CARGOS DE LAS FIESTAS PATRONALES DE LA CIUDAD DE DIRIAMBA, NICARAGUA
}

Mario Miguel Cienfuegos Narváez

\begin{abstract}
Resumen
El presente ensayo hace un esbozo de las fuentes teóricas referidas a los sistemas de cargos, desde la perspectiva de los protagonismos sociales, como podemos clasificarlos y operar con ellos metodologías que planteen el auto-reconocimiento entre pares y caminos por andar para mejorar el futuro. Es así que se presentan los elementos teóricos y metodológicos que marcan los pasos andados y por andar en esta temática.
\end{abstract}

Palabras Claves: Protagonismos, Fiesta patronal, sistema de cargo

Abstract

This essay outline of the theoretical sources that relate to the cargo systems from the perspective of social roles, we can classify and operate with them methodologies that pose self-peer recognition process and paths to improve the future. Thus, the theoretical and methodological elements that mark the steps walked and walking in this area are presented.

40 Keywords: Protagonism, religious festivities, cargo systems

\section{Introducción}

$\mathrm{E}$ 1 presente ensayo trata la vinculación de los protagonismos dentro del sistema de cargos de la fiesta patronal, celebrada en el mes de enero en el municipio de Diriamba, departamento de Carazo en la república de Nicaragua.

Se inicia con un punto de partida, donde se aclara la toma de posición del autor, así como un pequeño recorrido sobre la situación histórica de los protagonismos, sus transformaciones, combinaciones $\mathrm{y}$ retos desde el análisis aquí señalado.

Es importante destacar la discusión teórica presente en lo referido al sistema de cargos, mismo que sirve de escalón para hacer una propuesta propia que refleja la realidad de estos, en la fiesta patronal del municipio en cuestión.

Se describen los tipos de protagonismo vinculados al sistema de cargos y la fiesta patronal, haciendo especial énfasis en las características, así como su quehacer en la fiesta, las formas de elección. Todo ello se resume finalmente en un cuadro comparativo.

Con los datos anteriores es que se presenta a continuación una propuesta metodológica a manera de taller con los protagonistas identificados, esta con el objetivo de permitirles a ellos mismos reconocer sus fortalezas y debilidades; así como proyectar la visión de futuro real y alcanzable a la que pueden acceder. Finalmente se señala la bibliografía que se 
citó y referenció para la fundamentación del trabajo.

\section{Punto de partida !Con Diriangén no estaban en cero!}

Para iniciar este ensayo se dejan claros los considerandos que guían el mismo, como marco teórico-metodológico para explorar los protagonismos en el sistema de cargos de las fiestas patronales de la ciudad de Diriamba, Carazo, Nicaragua. El punto de partida básico es el reconocimiento de que en tiempos de la aparición del europeo en las tierras dominadas por el teyte Diriangén, en el primer cuarto del siglo XVI, los pueblos originarios ya tenían sus propias formas de organización, sus propias formas culturales. Entonces mezclaron sus particulares formas organizativas como posibilidades de resistencia al poder foráneo. Es útil releer al mismo Manuel Castells (2013) para revisar las pistas que nos da en relación con ciertas formas propias que se pusieron en juego.

\section{¿Sistema de cargos? Buscando entre las definiciones}

En el sistema de cargos veremos reflejados diversos protagonismos. Entre las diferentes definiciones sobre el sistema de cargos, ciertos autores lo refieren a partir de la estructura y sus características, como Sol Tax (1937), o bien como defensa ante formas políticas ajenas a la comunidad como el caso de la iglesia y la administración municipal, Wolf (1959).

Otros la definen como una forma de control de las riquezas por parte de la comunidad, de manera que asume el cargo quien más riquezas materiales posee y así hay una distribución de estas, Chance y Tylor (1987). Cerramos citando a Frank Cancian (1976) quien habla de manera exclusiva de la participación de hombres en un sistema cívico religioso con jerarquía, propio de las comunidades indígenas.

En este sentido se apunta que el sistema de cargos en Diriamba, tiene la característica de insertarse en una comunidad urbana, donde hay participación activa de hombres y mujeres con cargos jerárquicos en la estructura. Quienes asumen el cargo no necesariamente poseen bienes materiales, es decir no se eligen por capacidad económica, sino por su lugar dentro de las redes familiares, de amigos y comunitarias que estos tengan para costear los gastos que involucra la fiesta.

De lo anterior nos atrevemos a definir el sistema de cargos para la fiesta de Diriamba como una organización que posee jerarquía y estructura, con carácter cívico - religioso, cuyo origen se remonta a tiempos de la aparición de los europeos en tierras de dominio de comunidad indígena, bajo la denominación de mayordomías, cuyos miembros poseen redes familiares, de amigos, vecinales y comunitarias, insertadas en una comunidad urbana y con participación plena de hombres y mujeres. El sistema de cargos funciona todo el año para asegurar la fiesta patronal anual y todo lo que esta implica, comidas, bailes, trajes, procesiones, limosnas, pagos de promesas. En síntesis el resguardo de las tradiciones de la religiosidad popular del pueblo diriambino.

Los miembros del sistema de cargos o protagonistas individuales, son personas que forman parte de un colectivo de personas que en representación del pueblo administran diferentes momentos rituales de la fiesta patronal y que a pesar de tener el riesgo de permearse ante poderes político-económicos como la iglesia, la alcaldía; su resistencia le da valor y sentido ante el pueblo. 
Construyendo significados: autonomía y resistencia en el sistema de cargos.

El sistema de cargos surge como un espacio de autonomía frente al poder colonial de la corona española, si bien es cierto se cobijan bajo la iglesia cubren al mismo tiempo sus propias formas de poder, en este sentido el reflejo se hace notar por medio de las mayordomías de fiesta, de bailes, patronas, comité de fiesta, priostes y cabildo real de san Sebastián.

Manuel Castells (2013) refiere que la comunidad tiene una función emocional en sí misma, de estar juntos con otros, sin formar de manera obligatoria una comunidad. Para este caso, quien escribe no necesariamente concuerde con esta afirmación, debido a que no solo son las formas propias de organización de los pueblos originarios, como tales, las que estuvieron en el vaivén de los nuevos retos surgidos por la aparición del europeo, sino que toda la comunidad se vio involucrada como un colectividad.

Para Alejandro Dávila Bolaños (1990) Diriamba y la meseta de los pueblos ${ }^{1}$ estaba controlada bajo una forma de gobierno matriarcado, incluso señala que las mujeres hicieron una verdadera "huelga de úteros" que consistió en que la indígena violada y embarazada por un español se auto-inmolaba para no parirles esclavos a los recién llegados. Es decir para el caso que nos atañe, la función emocional aquí presentada crea un sentimiento de solidaridad, unidad, valor y resistencia frente a las formas de poder exógenas. Todo el conglomerado social se puso en peligro desde un primer momento.
Un elemento sustancial que se transforma es el ejército de Diriangén, explica Dávila Bolaños (1990). Este ejército armado de flechas y macanas de piedra, guerreó ferozmente contra el europeo, El ataque de Diriangén demostró en principio la decisión de no aceptar la imposición de una cultura y religión extraña, sumado al valor de enfrentarse a un desconocido que venía dotado de un animal nuevo en nuestras tierras y de armas de fuego jamás vistas.

Entonces este ejercito que defendía estas tierras, se transforma en el custodio del santo, de manera que se mimetizó al teyte Diriangén en la fiesta de San Sebastián, pues en todo caso el santo es visto como un trofeo de guerra, por ser una posesión de los recién llegados bajo el dominio del pueblo de Diriangén. Precisamente la imagen de San Sebastián se presenta martirizada por flechas.

Así lo confirma Charles Gibson (1964) al referirse a la importancia de poseer las imágenes por parte de los pueblos originarios: "las imágenes de los santos, las pinturas y los objetos de devoción desempeñaban un papel importante en la vida de los indígenas. La imagen que cada comunidad veneraba era una encarnación del sentido interior del pueblo" (Gibson, 1964:138)

La experiencia en antropología señala que en términos de la religiosidad popular en América latina, los dioses y los espíritus de la naturaleza fueron traspuestos por santos de la iglesia católica, de manera que las celebraciones patronales en su mayoría tienen un precedente indígena. Los

1 La meseta de los pueblos en la actualidad comprende los departamentos de Carazo, Masaya y Granada, todo el territorio se considera que fue dominio del teyte Diriangén. 
europeos en un primer momento fueron vistos como dioses.

Para los pueblos del pacífico de Nicaragua, la historia cuenta otra experiencia. A como se señala en la Historia militar precolombina y colonial publicado en la web por el Ejército de Nicaragua (2009), nuestros pueblos originarios no vieron a dioses en los europeos: "hay que destacar que los indígenas de nuestro territorio no consideraron a los españoles como dioses, a diferencia de otros grupos en América" (Ejército de Nicaragua; 2009: 01)

Despierta curiosidad el caso de Diriamba. El ejército de Diriangén se transforma en cabildo real. Entonces la fiesta se celebra en memoria de Diriangén a través de XipeTotec sincretizado en San Sebastián, Esto gracias a una comparación de calendarios indígenas y ritual católico presentado por Dávila Bolaños (1990) y Rivera González (2002).

De todo lo planteado hasta ahora, se puede encontrar una idea resumida en: otros mundos reales son posibles, siempre que nos asomemos y nos asumamos como sujetos y dueños de nuestro propio destino. Nuestra ventana es posible en la medida que contrastamos y afianzamos nuestra visión de nosotros mismos, y no nos vemos cómodamente desde la ventana tradicional que han construido los verdaderos otros de todos nosotros.

\section{Elementos del perfil de los protagonistas}

En esta parte se describe a los protagonistas claves para la fiesta, las formas y cualidades que imperan en la elección de cada uno de estos, así como los involucrados para la elección de los mismos. De tal manera que se reconocen los protagonistas, sus tipos, características y su quehacer diario como militancia protagónica.

\section{Los protagonistas:}

El santo: generalmente el protagonista. Hace referencia a personas vivas, reales que habitan entre la comunidad. En este sentido surge la hipótesis anteriormente planteada: si San Sebastián es un trofeo de guerra para Diriangén, entonces año con año se re momora, durante las fiestas a Diriangén y su ejército transformado en la actualidad en el baile del Toro Guaco ${ }^{2}$ tomando el protagonismo principal. Es protagonista líder porque a pesar de no ser una persona viva, está presente en el imaginario colectivo del pueblo. Tiene roles sobrenaturales que persiguen incidir en el futuro de los pobladores, quienes acuden a él por su intercesión.

Si la hipótesis planteada es constatada, San Sebastián es un trofeo de guerra para Diriangén. La elección del santo como protagonista líder empieza con un ritual donde los cautivos en guerra eran desollados y otros flechados. Así lo señala Rivera González (2002) cuando asegura que, "durante la fiesta del desollamiento, algunos de los cautivos eran objeto de flechamiento por parte de los mismo guerreros. Es decir se les disparaban flechas al cuerpo, simbolizando la fecundación de la tierra con la sangre derramada" (Rivera, 2002: 266)

Precisamente la fiesta del desollamiento se daba en honor a XipeTotec "nuestro señor el

2 Toro guaco, es una danza tradicional de la ciudad de Diriamba, que se luce en las fiestas patronales, los bailantes se dividen en dos hileras, su paso asemeja un serpenteo que abre paso a la procesión del santo san Sebastián, se acompaña de un músico a ritmo de pito y tambor, cada bailante lleva una sonaja. Al centro de las hileras baila el mandador y una armazón que representa el esqueleto de un toro. 
desollado" representante de la primavera, cuando la tierra en signo de fertilidad, reverdecía nuevamente. Describe Rivera (2002) que estas personas hacían fiesta durante veinte días, igual como dura la fiesta de San Sebastián [del 16 de enero 2 de febrero:]. Luego los guerreros iban de casa en casa pidiendo limosnas, y lo recaudado era repartido entre ellos. Esta escena es muy similar a lo acaecido año con año en las fiestas patronales de Diriamba, en las personas del cabildo real.

Cabildo real de San Sebastián: Compuesto por 13 hombres quienes se encargan de dar por pagadas las promesas de los devotos, levantada de banco $^{3}$, porta estandarte, cajas, custodios del santo y la limosna, correspondiendo a la parte de negociación del pueblo con la iglesia. Se enmarcan en el rol de Protagonismo impulsor porque han transformado ciertos elementos. Como ejemplo, en la actualidad se prohíbe a los miembros del cabildo la ingesta de licor, esto hace de las celebraciones y cuido del santo acciones ejemplares y efectivas.

La elección de los miembros del Cabildo tiene como característica ser autónoma, en otras palabras, son los mismos miembros del cabildo quienes proponen candidatos para su elección. El papel de la iglesia representada en la persona del sacerdote, únicamente es de escuchar y conocer las decisiones tomadas por el cabildo.

\section{Mayordomías}

Mayordomo: hombre - persona encargada de reunir los recursos en especie o dinero, para hacer los cuatro primeros días de comida desde la bajada del santo. Su rol es de Protagonismo ejemplarizante porque los mismos pobladores tienen conciencia que el asumir esta responsabilidad requiere de mucho esfuerzo, tiempo, dedicación, compromiso con el pueblo y el santo.

En ocasiones, la posición económica y el prestigio social del Mayordomo elegido es señalada como importante, porque los gastos de la fiesta suelen ser muy altos. La honestidad en el manejo de recursos y dinero es un punto de referencia tomado en cuenta. La elección del cargo se hace en acto público, el dos de febrero durante la celebración de una misa. El sacerdote lo presente y al finaliza la elección, le impone una banda a la persona elegida, quien de inmediato acepta el cargo y se compromete a cumplirlo con responsabilidad.

Patrona: mujer- persona encargada de reunir los recursos en especie o dinero para la comida para los últimos cuatro días de comida con que se da por finalizada la fiesta del año. Su protagonismo es ejemplarizante porque los mismos pobladores afirman que asumir esta responsabilidad requiere mucho esfuerzo, tiempo, dedicación, compromiso con el pueblo y con el santo.

La diferencia entre el Mayordomo y la Patrona, además de la condición sexual, está relacionado con los tiempos en que se divide la fiesta. El mayordomo abre la fiesta el 16 de enero está presente hasta el 20 de enero; la patrona asume las fiesta del 24 al 27 de ese mismo mes porque son los días de elaborar y compartir la comida con la comunidad.

Comité de fiesta: es asumido por hombres y mujeres, cuando el cargo de Mayordomo y Patrona está vacante. La presencia y el peso de este Comité están sujetos al

3 La levantada de banco consiste que el alférez mayor como representante del cabildo real, da por pagada la promesa si este está satisfecho con los dones ahí repartidos. 
nombramiento y/o la elección de los cargos mencionados. De no contar con el Mayordomo ni Patrona, los promesantes y tradicionalistas de reconocida trayectoria y prestigio social, suelen agruparse en el Comité de fiesta para asumir dicha responsabilidad.

Su protagonismo es ejemplarizante porque los mismos pobladores afirman queasumir esta responsabilidad requiere mucho esfuerzo, tiempo, dedicación, compromiso con el pueblo y con el santo. La conformación del Comité se hace por medio de reuniones auto-convocadas y luego es presentado a la comunidad durante una misa el 2 de febrero. La iglesia oficializa el cargo por medio de la imposición de bandas a estos miembros.

Mayordomos de baile: son hombres o mujeres que tienen la responsabilidad de organizar año con año los bailes que acompañan al santo. Se pueden mencionar el baile del Toro Guaco, principal danza de la procesión y la fiesta, las Inditas Cantoras, El Güegüense, El Gigante. Todo esto varía en número, habiendo hasta 3 conjuntos de cada baile. La elección de estos bailes es personal, porque tiene como punto de partida "favores" recibidos por el santo. Su distintivo es una banda colocada en la misa del 2 de febrero. Su protagonismo es impulsor, pues gracias a ellos se mantienen la parte organizativa de los bailes.
Fiestero: a pesar de tener un nombre en singular, el fiestero está compuesto por las familias y las redes vecinales y de amigos quienes preparan una enramada para ofrecer comidas y bebidas a los promesantes. Los fiesteros pueden variar de año en año, según la cantidad de promesas. Su protagonismo es impulsor por ser familias quienes se encargan de la atención de los asistentes a la fiesta en sus hogares, de manera que la permanencia de estos sea mayor y más reconfortante,

La elección de los asistentes obedece a una decisión personal, animada por la idea de continuar las tradiciones familiares o locales, o bien "favores o promesas" con el santo. Los fiesteros son presentados inicialmente en la misa del 2 de febrero, no tienen distintivo, y puede auto-nombrarse cualquier día del año sin ser presentado en misa.

Como características generales de los cargos antes descritos, se pueden mencionar los que aglutinan los distintos tipos de protagonismos en la fiesta patronal: conservador de las tradiciones religiosas, responsable de actividades con la comunidad o el pueblo, aglutinador de las expectativas de la comunidad, prestigio social. 
Tabla resumen de los protagonismos en la fiesta patronal de Diriamba

\begin{tabular}{|c|c|c|c|c|c|}
\hline $\mathbf{N}^{\circ}$ & Protagonista & Característica & Que hacer diario & Elección & $\begin{array}{c}\text { Calidad de } \\
\text { protagonismo }\end{array}$ \\
\hline 1 & El santo & $\begin{array}{l}\text { Aglutinador del } \\
\text { pueblo (comunidad) }\end{array}$ & $\begin{array}{l}\text { Reside físicamente } \\
\text { en la iglesia, pero } \\
\text { forma parte de la } \\
\text { cosmovisión r del } \\
\text { diriambino }\end{array}$ & $\begin{array}{l}\text { Un trofeo de guerra } \\
\text { para Diriangén, en } \\
\text { la fiesta indígena } \\
\text { XipeTotec }\end{array}$ & Líder \\
\hline 2 & $\begin{array}{l}\text { Cabildo real de } \\
\text { san Sebastián } \\
(13 \text { hombres })\end{array}$ & $\begin{array}{lr}\begin{array}{lr}\text { Custodios de la } \\
\text { imagen. }\end{array} & \\
& \\
\text { Certifican } & \text { el } \\
\text { cumplimiento } & \text { de } \\
\text { promesas. } & \\
\end{array}$ & $\begin{array}{l}\text { Diálogo con la } \\
\text { iglesia y el pueblo. } \\
\text { Organizar las visitas } \\
\text { del santo. }\end{array}$ & $\begin{array}{l}\text { Son elegidos } \\
\text { ellos mismo, } \\
\text { postulación }\end{array}$ & Impulsor \\
\hline 3 & $\begin{array}{l}\text { M a y o r d o m o } \\
\text { (hombre) }\end{array}$ & $\begin{array}{l}\text { Reúne los recursos } \\
\text { en especie o dinero } \\
\text { prestigio social, y } \\
\text { que esté dispuesto } \\
\text { a asumir esta } \\
\text { responsabilidad. } \\
\text { Esfuerzo, tiempo, } \\
\text { d e d i c a c ó n , } \\
\text { compromiso con el } \\
\text { pueblo y con el santo }\end{array}$ & $\begin{array}{l}\text { Forman parte de } \\
\text { redes familiares, de } \\
\text { amigos, vecinales - } \\
\text { comunitarias, para } \\
\text { lograr los recursos }\end{array}$ & \begin{tabular}{|l} 
En acto público \\
el dos de febrero \\
en una misa, es \\
presentado por el \\
sacerdote quien le \\
impone una banda, \\
el cargo lo asume la \\
persona que tiene \\
conocimiento de su \\
propio \\
La banda es su \\
distintivo
\end{tabular} & Ejemplarizante \\
\hline 4 & Patrona (mujer) & & & & \\
\hline 5 & $\begin{array}{|lr|}\text { Comité de Fiesta } \\
\text { (hombres } \\
\text { mujeres) }\end{array}$ & & & & \\
\hline 6 & $\begin{array}{l}\text { Mayordomos de } \\
\text { bailes (hombre o } \\
\text { mujer) }\end{array}$ & $\begin{array}{l}\text { Conservador de } \\
\text { las tradiciones } \\
\text { religiosas } \\
\text { Responsable con las } \\
\text { actividades de cara } \\
\text { al pueblo } \\
\text { Prestigio social }\end{array}$ & $\begin{array}{l}\text { Organizan los } \\
\text { bailes, ensayos, y } \\
\text { todo lo concerniente }\end{array}$ & $\begin{array}{l}\text { Individual. } \\
\text { Pago de promesas } \\
\text { porfavores recibidos. } \\
\text { Reconocidos por la } \\
\text { iglesia y el pueblo } \\
\begin{array}{l}\text { La banda es su } \\
\text { distintivo }\end{array}\end{array}$ & Impulsor \\
\hline 7 & 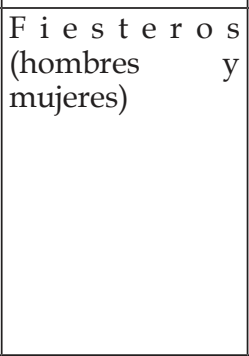 & & $\begin{array}{|lr|}\text { Preparan } & \text { una } \\
\text { enramada } & \text { para } \\
\text { ofrecer } & \text { comidas } \\
\text { y bebidas a los } \\
\text { promesantes }\end{array}$ & $\begin{array}{l}\text { Individual } \\
\text { Presentados en la } \\
\text { misa del } 2 \text { de febrero } \\
\text { No tienen distintivo, } \\
\text { y puede auto- } \\
\text { nombrarse cualquier } \\
\text { día del año sin ser } \\
\text { presentado en misa. }\end{array}$ & \\
\hline
\end{tabular}




\section{Propuesta metodológica: espacio para reflexionar y crear el perfil de los protagonistas}

Aquí se presenta a manera de ejemplo, una actividad propuesta al lector dirigida a la creación de la foto actual y de futuro de los protagonismos en la fiesta patronal y el sistema de cargos en Diriamba. La tradición marca el perfil mínimo de estos protagonistas, y cada vez que se seleccionan hay reflexiones, entonces surgen preguntas: ¿Cómo hacer una foto actual de estos protagonistas? ¿Acaso no podríamos generar un espacio para ello que a la vez permita reflexionar los perfiles y afirmar el valor de la tradición con alguna proyección ante el entorno actual y el venidero?

Para estos propósitos involucramos talleres con Meta plan, donde se generen ideas para construir de manera colectiva la foto actual y de futuro de los protagonismos involucrados en la fiesta patronal y el sistema de cargos. Esta meta plan se presenta como un método de moderación grupal para la búsqueda de respuestas a interrogantes, de ideas, soluciones, desarrollo de opiniones, recomendaciones, planes de acción. Todo ello en el marco de un aprendizaje de interacción para el aprovechamiento de la motivación intrínseca que acarrea.

\section{Pasos del taller:}

1. Antes del Taller

a. Búsqueda de local y logística para la realización del taller

b. Convocatoria a los protagonistas antes mencionados

c. Preparación del local y logística para la realización del taller

d. Definición de la técnica: Técnica de animación, su objetivo central es cohesionar, crear una ambiente fraterno y participativo.

2. Durante el taller:

e. Bienvenida a los participantes

f. Explicación de los objetivo y metodología del taller

g. Ejecución del taller(en detalle más abajo)

3. Actividades de cierre:

h. Recolección de información

i. Clasificación colectiva de la información

j. Plenario sobre los hallazgos.

\section{Descripción del proceso del taller:}

Se les pide a los participantes que dibujen la silueta de un compañero en un papelón, con la cabeza, oídos, manos y pies bien definidos. De manera que por medio de tarjetas en manos de los participantes escriban las siguientes ideas:

Cabeza: Lo que considera más importante de él/ella como protagonista.

Oído izquierdo: Lo que considera que ha escuchado y no le ha gustado de él o ella misma como protagonista.

Oído derecho: lo que sí le ha gustado escuchar de él/ella como protagonista.

Mano derecha: acción que considera ha sido efectivas que él/la protagonistas ha hecho de manera positiva.

Mano izquierda: acción que considera no ha sido efectivas que él/la protagonista ha hecho.

Pie derecho: acciones pendientes por realizar

Pie izquierdo: metidas de pata.

Esta primera parte es útil para recoger ideas auto reflexivas del estado del protagonismo. Este mismo ejercicio 
permitirá establecer el protagonismo ideal o de futuro que se espera. Se puede formar y retomar ciertos elementos del proceso anterior como la silueta y las tarjetas, pero ubicando los siguientes puntos:

Cabeza: Conocimientos, pensamientos, juicios, saberes.

Corazón: sentimientos, miedos, aspiraciones, deseos, actitudes.

Brazos: habilidades, destrezas, aptitudes, pericias.

Pies: la relación con la fiesta y la vida real, los caminos a seguir.

Ombligo: su integración con la naturaleza, la cosmovisión y la cosmogonía.

Con esta misma metodología se harán ambos talleres. El número 1: será con los protagonistas identificados por $\mathrm{mi}$ persona. El número 2: estará integrado por personas que forman parte de la red del protagonista. Las interrogantes planteadas con la figura humana, cambiaran según los intereses y los participantes, pero por efectos de comparación y contraste se usara la misma metodología. De manera que se persigue obtener las fotos actuales y futuras de los protagonistas.

\section{Referencias Bibliografía}

CANCIAN, F. (1976) Economía y prestigio en una comunidad maya. México: INI

CASTELLS, M. (2013) Conferencia magistral: Enredados para la libertad. Movimientos sociales en la era de Internet. México: Universidad del Valle de Atemajac, Jalisco. En http://www.youtube. com $/$ watch? $v=$ MPN_EpQ0ONM [visitado el 26 de diciembre 2013]
CHANCE, J.; TAYLOR, W. (1987) "Cofradías y cargos: perspectiva histórica de la jerarquía cívicoreligiosa mesoamericana", Boletín Oficial del Instituto Nacional de Antropología e Historia. Nueva Época, núm.14, Mayo-Junio.

DÁVILA BOLAÑOS, A. (1990) Nicaragua prehispánica. Estelí: ISNAYA

Ejército de Nicaragua (Eds). (2009) Memoriasdelejército2009.En:http:/ / www.ejercito.mil.ni/contenido/ relaciones-publicas/publicaciones/ docs/memoria-1979-2009-026-049. pdf [visitado el 28 de diciembre 2013].

GIBSON, CH. (1964) Los aztecas bajo el dominio español (1519 - 1810) México: Siglo XXI

GIMÉNEZ, G.. (2006) La cultura como identidad y la identidad como cultura. México: Instituto de Investigaciones Sociales de la UNAM

FERGUSON, A. (1998) ¿Puede el desarrollo propiciar el empoderamiento y la liberación de las mujeres? Amherst: University of Massachussets.

RIVERA GONZÁLEZ， J. G. (2002). "Representación y significados actuales de la festividad del carnaval de Xhitas en Jilotepec". En Eduardo Andrés Sandoval Forero, Hilario Topete Lara y LeifKorsbaek (Eds): Cargos Fiestas y Comunidades. México: UAEM

TAX, Sol (1937) "The Municipios of the Midwestern Highlands of Guatemala", American Anthropologist, 39. 
ULLOA, L. F. (2009a) Protagonismos desde atrás, desde adelante, desde todas partes.Managua: Hispamer.

......(2013b). Los espacios públicos y su interés para el protagonismo y la participación ciudadana. En http://es.scribd.com/ doc/30409837 / LOS-ESPACIOSPUBLICOS-Y-SU-INTERES-PARAEL-PROTAGONISMO-Y - LAPARTICIPACION-CIUDADANALuis-Felipe-Ulloa [visitado el 04 de enero 2014]

WOLF, E. (1959) Sons of the Shaking Earth.

Chicago: University of Chicago Press 